\title{
CLIMATE SIGNATURE OF SOLAR IRRADIANCE VARIATIONS: ANALYSIS OF LONG-TERM INSTRUMENTAL, HISTORICAL, AND PROXY DATA
}

\author{
GERRIT LOHMANN,* NOREL RIMBU and MIHAI DIMA \\ Bremen University, Center for Marine Environmental Sciences, Klagenfurter Str., 28359 Bremen, Germany
}

Received 3 March 2003

Revised 26 March 2004

Accepted 28 March 2004

\begin{abstract}
The signature of solar irradiance variations on decadal-to-centennial climate variability is analysed by means of statistical analysis of long-term instrumental, historical, and proxy data sets. Solar variations associated with the Schwabe, Hale, and Gleissberg cycles are detected by their spatial patterns in sea-surface temperature and sea-level pressure. Different statistical methods for instrumental and proxy data show that the mode related to solar irradiance fluctuations on multidecadal time scales (Gleissberg cycle) is distinct from the Atlantic multi-decadal mode associated with ocean circulation changes. From this, one can infer the degree to which solar variability has contributed to long-term temperature variations during the instrumental and pre-instrumental era. Copyright (c) 2004 Royal Meteorological Society.

KEY WORDS: solar irradiance; multidecadal climate variability; pattern analysis; Gleissberg cycle; modes distinction; instrumental data; proxy data; thermohaline circulation
\end{abstract}

\section{INTRODUCTION}

The radiation output from the Sun does vary on a wide range of time scales, from days to billions of years. Beyond the very slow evolution of the Sun, i.e. as a hypothesis of stellar evolutionary theory on a $10^{10}$ year time scale, there is direct observational evidence for shorter term variations in solar irradiance linked to sunspots. Sunspots are huge magnetic storms that show up as cool (dark) regions on the Sun's surface. They occur in cycles, with their number and size reaching a maximum approximately every 11 years (Schwabe cycle). The length of the Schwabe cycle defined through the interval between successive sunspot maxima is modulated over a period of about 70-100 years (Gleissberg cycle) (Hoyt and Schatten, 1997; Beer et al., 2000). As an example, during the climax of the Little Ice Age (1645-1715) there were few sunspots, the socalled Maunder Minimum (Hoyt and Schatten, 1997). Since sunspots are easily visible and there are records of their abundance extending back to the early 1600s, sunspots are the most widely used proxy for solar activity reconstructions.

The variations of total solar irradiance associated with the 11 year sunspot cycle have been assessed with some accuracy using satellite data for more than 20 years. The estimation of earlier solar irradiance fluctuations is via a calibration of satellite measurements. Several recent reconstructions estimate variations in solar irradiance of about 0.24 to $0.30 \%$ on decadal to centennial time scales (Lean et al., 1995, 1997; Hoyt and Schatten, 1993), compared with a $0.1 \%$ modulation during the 11 year solar cycle measured from satellites.

Modelling studies have applied the reconstructions of Lean et al. (1995) and Hoyt and Schatten (1993) in order to estimate the effect of solar irradiance fluctuations on climate. Cubasch et al. (1997) performed simulations with a global coupled ocean-atmosphere circulation model to study the potential impact of solar variability on climate. Results indicate that the near-surface temperature simulated by the model is dominated

* Correspondence to: Gerrit Lohmann, Bremen University, Center for Marine Environmental Sciences (MARUM), Klagenfurter str., 28359 Bremen, Germany; e-mail: gerrit.lohmann@dkrz.de

Copyright (C) 2004 Royal Meteorological Society 
by the long periodic solar fluctuations (Gleissberg cycle), with global mean surface temperatures varying by about $0.5 \mathrm{~K}$. Their results show that solar variability and an increase in greenhouse gases both, to a first approximation, induce a comparable pattern of surface temperature change, i.e. an increase of the land-sea contrast. Compared with a more uniform warming associated with the increase in greenhouse gases, the solar-induced warming pattern is more centred over the subtropics through an increased flux of shortwave radiation in cloud-free regions.

Haigh (1999) presents atmospheric circulation model results for the influence of the 11 year solar cycle on the climate of the lower atmosphere. In her model, solar forcing is represented by changes in both incident irradiance and stratospheric ozone concentrations, where the latter has the stronger impact. A pattern of response is found in which the tropical Hadley cells weaken and broaden, and the subtropical jets and midlatitude Ferrel cells move poleward for high irradiance. The changes in dynamics cause subtropical warming and a characteristic vertical band structure of mid-latitude temperature changes.

A recent mechanistic picture of solar radiation for climate variability is provided by modelling studies of Shindell et al. (2001b). In their atmospheric model coupled to a mixed layer ocean they find a tropical/subtropical warming which induces a warmer tropical upper troposphere via moist convective processes. This leads to an increased latitudinal temperature gradient in the stratosphere, resulting in enhanced lower stratosphere westerly winds, and causes increased angular momentum transport to high latitudes and enhanced tropospheric westerlies. The dynamical result is attributed to an interaction between ultraviolet radiation and ozone in the stratosphere (Balachandran et al., 1999) and a downward propagation of stratospheric events (Baldwin and Dunkerton, 1999; Christiansen, 2000).

Here, we address the question of whether solar irradiance variations can be detected in the instrumental record, historical, and high-resolution proxy data sets. Special emphasis is placed on the pattern related to natural climate variability and solar variability in order to identify their relative importance for observed multidecadal temperature variations. Varved sediments that accumulate within the bottom anoxic waters provide a detailed record of climate change on annual to multi-centennial time scales. These records provide evidence of a strong decadal to centennial climate variability (Black et al., 1999).

This paper is organized as follows. The data are introduced in Section 2. Results are presented in Section 3 and discussed in Section 4. Finally, conclusions are given in Section 5.

\section{DATA}

The approach is based on statistical data analysis of historical and instrumental surface data. We want to address the question as to which pattern in these surface quantities is associated with solar forcing variations. The solar irradiance signature (Lean et al., 1995) is obtained from information contained in long instrumental data sets for sea-surface temperature (SST) given by Kaplan et al. (1998), Jones (1994), Parker et al. (1994, 1995), and for sea-level pressure (SLP) given by Trenberth and Paolino (1980), Jones (1987), and Luterbacher et al. (2002).

The SST data set used for most applications in this manuscript covers the period 1856-1991 (Kaplan et al., 1998). The spatial resolution is $5^{\circ} \times 5^{\circ}$ and the data are now updated to the period 1856-2000. Large-scale atmospheric circulation pattern anomalies over the Northern Hemisphere are based on the SLP historical data set described by Trenberth and Paolino (1980). This data set is based on historical daily SLP maps from various sources. It has a $5^{\circ} \times 5^{\circ}$ horizontal resolution and covers the period 1899-2000. Furthermore, the Climatic Research Unit (CRU) data set, containing monthly mean SLP data on a $5^{\circ}$ latitude by $10^{\circ}$ longitude grid-point basis, has been utilized. The sources of the original chart data are given in Jones (1987) and are further discussed by Basnett and Parker (1997).

In order to cover the long time scales, reconstructions were applied of gridded monthly SLP fields back to 1659 for the eastern North Atlantic-European region $\left(30-70^{\circ} \mathrm{N} ; 30^{\circ} \mathrm{W}-40^{\circ} \mathrm{E}\right)$ of Luterbacher et al. (2002). This reconstruction is based on the combination of early instrumental station series and documentary proxy data from Eurasian sites. Under the assumption of stationarity in the statistical relationships, a transfer function derived over the 1901-90 period was used to reconstruct the 500 year large-scale SLP fields. 
As additional data, a palaeoclimate proxy time series covering the period AD 1165-1990 (Black et al., 1999 ) is used in the analysis. This time series provides a millennial record of ocean-atmosphere variability in the North Atlantic basin and originates from Cariaco basin $\left(10^{\circ} \mathrm{N}, 64^{\circ} \mathrm{W}\right)$, a large and deep ocean basin located on the continental shelf of Venezuela (Black et al., 1999). The record contains age and abundance (number of individuals per gram of sediment) for the planktonic foraminifera Globigerina bulloides. The age model is based on a combination of varve counts, ${ }^{210} \mathrm{~Pb}$, and accelerator mass spectrometry ${ }^{14} \mathrm{C}$ dates.

\section{RESULTS}

\subsection{Solar fingerprint in instrumental data}

The solar irradiance reconstruction of Lean et al. (1995) is displayed in Figure 1(a). Peak times of solar irradiance are seen around 1750, 1850 and 1950, with amplitudes higher at each peak. Low-energy periods are centred near 1700, 1810, 1900, and, less clearly, near 1970. The power spectrum of this time series is calculated using the multi-taper method (MTM; Thompson, 1982). The spectral analysis of the Lean et al. (1997) solar variability shows a trend and periodicities at about 11, 20, and 80 years (Figure 1(b)). This spectral composition explains more than $95 \%$ of solar variance. The specific cycles are called the Schwabe cycle (11 years), the Hale cycle ( 22 years), and the Gleissberg cycle (70-100 years). Motivated by these frequencies, three distinct time scales are considered separately in the analysis: 9-15 years, 17-30 years and longer than 30 years.

For data processing, boreal winter (December, January, February (DJF)) and annual means were calculated. The time series and observational data were band-pass filtered in the above-defined frequency intervals. No lag is applied. Prior to analysis the individual time series were detrended by removing the linear trend and normalized to unit variance. For the statistical analysis, statistical routines developed at the Max-Planck Institute for Meteorology in Hamburg were applied. Their background and several applications are described in textbooks (e.g. von Storch and Zwiers, 1999). For the calculation of degrees of freedom, serial correlation in the local time series has been taken into account (e.g. von Storch and Zwiers, 1999). Serial correlation occurs when residuals from adjacent measurements in a time series are not independent of one another.

3.1.1. The 9-15 year time scale. The correlation map between solar irradiance and SST on this time scale is shown in Figure 2(a). Significant correlation at the 90\% significance level is found for most points where the absolute value of the correlation for SST is above 0.35, which is mainly confined to regions in the Pacific Ocean (Figure 2(a)). The correlation maps with SLP data sets of Trenberth and Paolino (1980) and Luterbacher et al. (2002) show rather low correlation values and are not shown here.

3.1.2. The 17-30 year time scales. The correlation maps between solar irradiance and SST, and between solar irradiance SLP on the bi-decadal time scale are shown in Figures 2(b) and 3 respectively. For SST (Figure 2(b)), negative correlations in the central and western North Pacific Ocean, subtropical North Atlantic and eastern North Atlantic are detected in a similar way as for the decadal band (Figure 2(a)). Significant correlation at the $90 \%$ significance level is found for most points where the absolute value of the correlation for SST is above 0.6 (Figure 2(b)). The corresponding map with a 95\% significance level (not shown) does not strongly affect the extension of the striped areas in Figure 2(b).

The correlation map of SLP based on Jones (1987) shows a coherent large-scale annular pattern (Figure 3(a)). High values of solar radiative forcing are associated with a Northern Hemisphere circulation pattern with a low-pressure system over Europe and high pressure over the Arctic (Figure 3(a)), projecting partly onto that of the Arctic oscillation (Thompson and Wallace, 1998) in its negative phase. Consistent with this, warming over the Labrador Sea is related to the weaker influence of cold air from the northwest. The Aleutian low in the North Pacific is deepened in the 17-30 year frequency interval. The anomalous lowpressure systems in the North Pacific and Atlantic Oceans indicate cold air advection producing negative SST anomalies in the western parts of the oceans similar to that associated with the Arctic oscillation (Thompson 

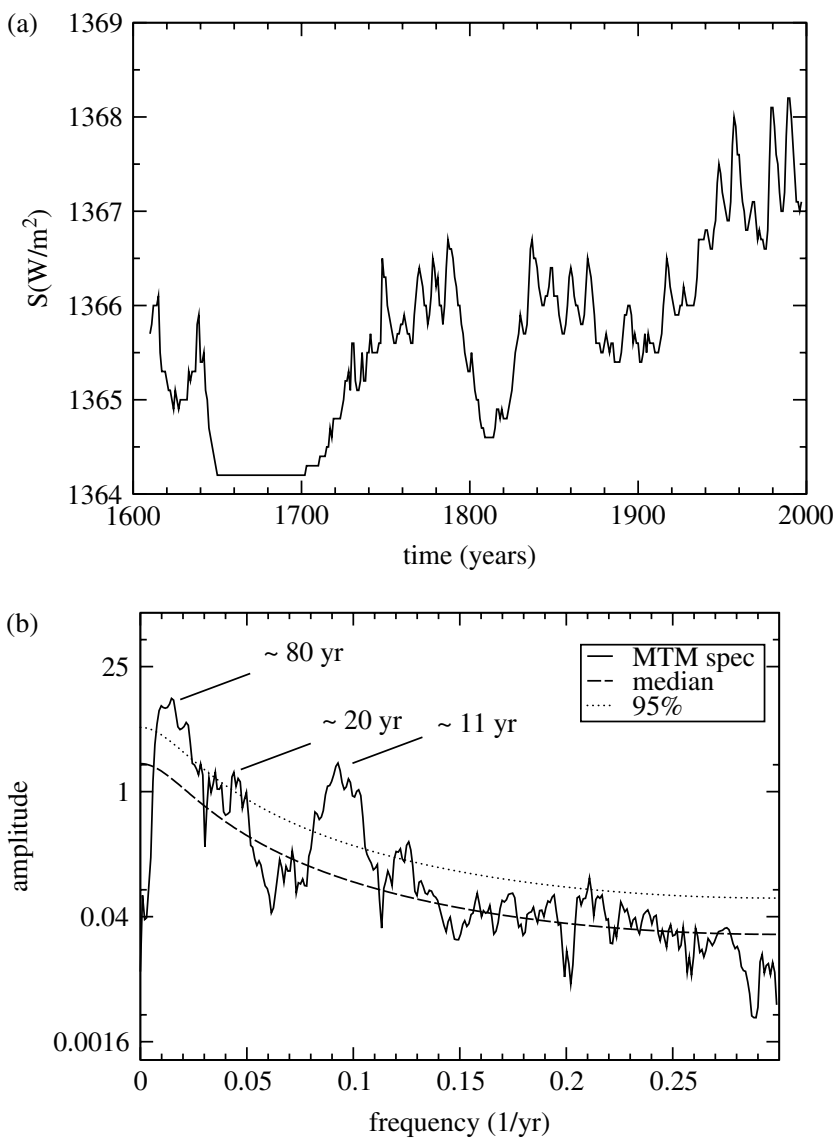

Figure 1. (a) Time series of solar irradiance $S$ according to the reconstruction of Lean $e$ al. (1998). (b) The MTM power spectrum of the detrended solar irradiance time series represented in (a). Best-fit noise background and the 95\% significance level relative to the null hypothesis of first-order autoregressive red-noise process are shown as dashed and dotted lines respectively

and Wallace, 1998). A consistent SLP pattern over Europe is indicated in Figure 3(b) by the analysis of the Luterbacher et al. (2002) data set.

3.1.3. Signature for time scales longer than 30 years. The correlation map between solar irradiance and SST (Kaplan et al., 1998) on this time scale is shown in Figure 2(c). For the multi-decadal time scale, the most significant temperature changes occur in the Pacific Ocean, with alternating bands of opposite signs, and in several regions of the Atlantic Ocean (Figure 2(c)). This structure is very similar to the correlation pattern in the decadal (Figure 2(a)) and bi-decadal (Figure 2(b)) bands.

\subsection{Separating multidecadal modes}

In order to evaluate the global variability pattern, we applied an empirical orthogonal function (EOF) analysis (e.g. von Storch and Zwiers, 1999) to the global SST data set provided by Kaplan et al. (1998). Prior to the calculation, a 25 year running mean was applied to the SST data. The first EOF (Figure 4(a)) has a very similar structure to the correlation map for solar irradiance and SST (Figure 2(c)), including a small centre of negative correlations at about $40^{\circ} \mathrm{N}$ in the North Atlantic.

The second EOF (Figure 4(b)) shows a monopolar structure for the North Atlantic resembling a multidecadal Atlantic mode (Deser and Blackmon, 1993; Delworth and Mann, 2000; Grosfeld et al., 2004). This multidecadal mode of climate variability is distinct from climate variability related to solar irradiance 
(a)

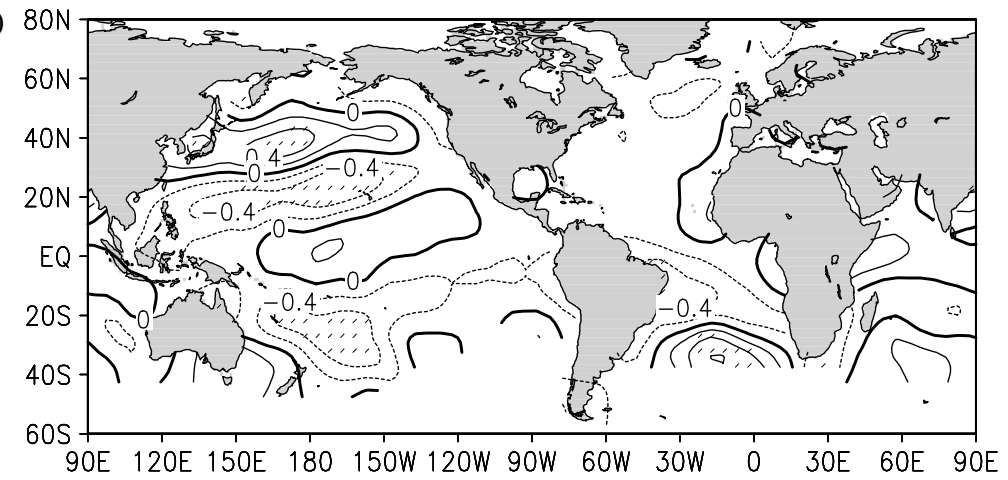

(b)

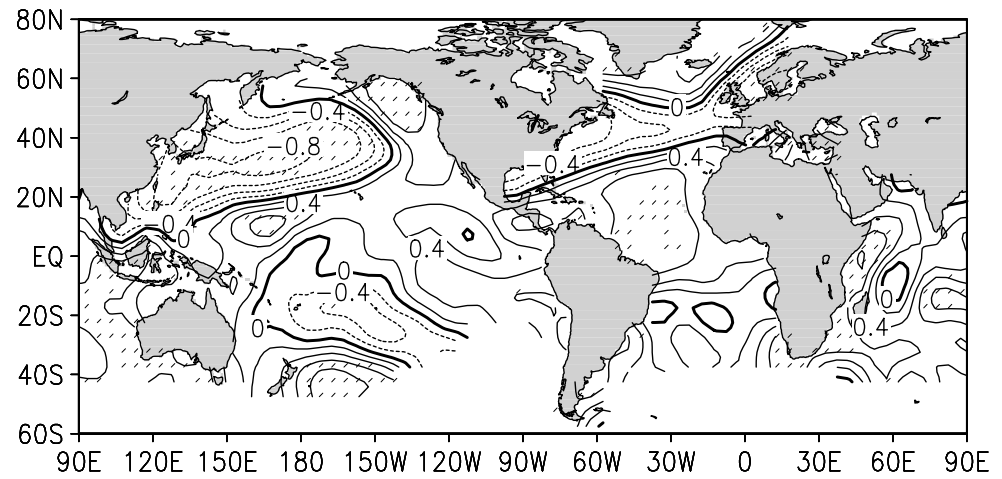

(c)

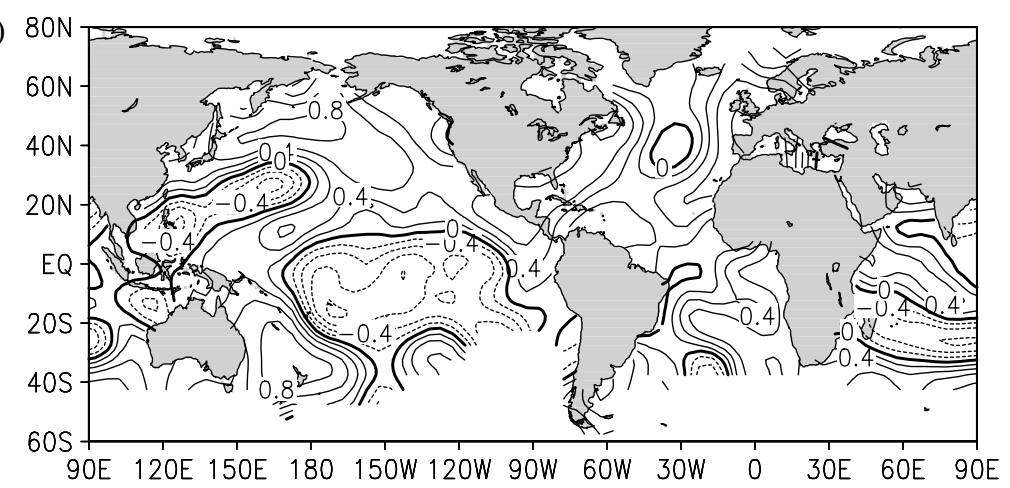

Figure 2. (a) Correlation map of solar irradiance (Lean et al., 1995) with SST (Kaplan et al., 1998). Data are linear detrended and filtered in the (a) 9-15, and (b) 17-30 frequency interval prior to the correlation. For (c), the data were detrended and smoothed with a 31 year running mean filter prior to the correlation. For (a) and (b), areas are striped where correlations exceed the $90 \%$ confidence level

variations. The signature of the SST pattern (Figure 4(b)) resembles the interhemispheric seesaw pattern associated with the Atlantic thermohaline circulation (Crowley, 1992; Stocker, 1998).

\subsection{Solar fingerprint in proxy data}

Motivated by the different modes identified by the EOF analysis, different multi-decadal time components and spatial signatures are calculated from the high-resolution Cariaco proxy record covering the last 800 years (Black et al., 1999). We have used singular spectrum analysis (SSA; Vautard and Ghil, 1989) to extract the dominant oscillatory components from time series. SSA spectral analysis is basically an EOF analysis in the time domain. As a first step, the long-term trend is removed by a preliminary SSA on the time series. 
(a)

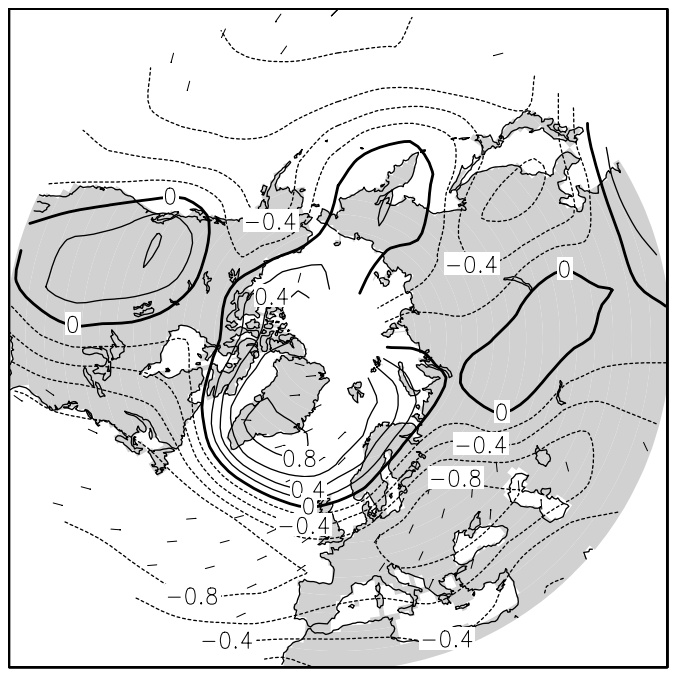

(b)

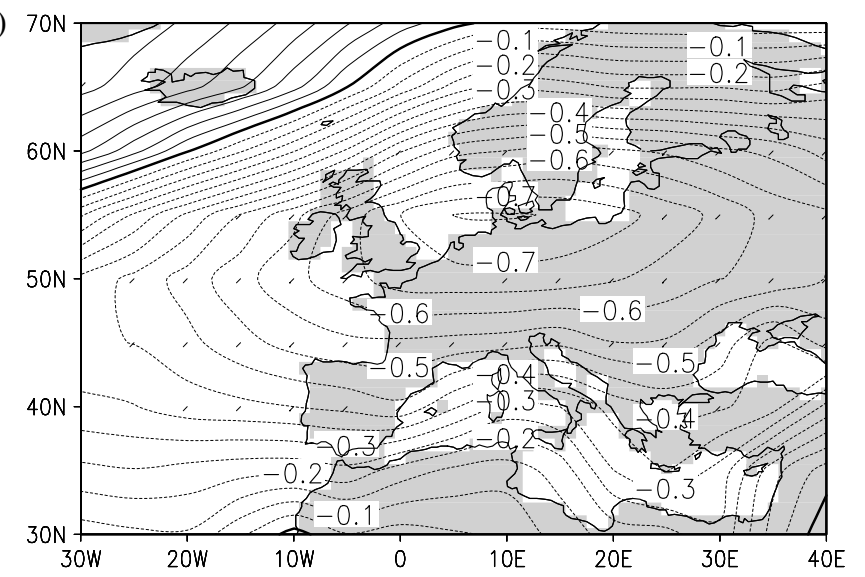

Figure 3. Correlation map of solar irradiance (Lean et al., 1995) and winter (DJF) SLP in the 17-30 year frequency band. (a) SLP for the period 1873-1997 (Jones, 1987). (b) SLP for the period 1659-1997 (Luterbacher et al., 2002). Areas are striped where correlations exceed the $90 \%$ confidence level

A new SSA is applied to the resulting time series using a 300 year window in order to resolve the multidecadal time scale. The analysis reveals that the first two periodic components obtained from the SSA have periods of 250 and 125 years. The third and fourth components show multi-decadal variability with periods of 83 years and 67 years explaining $8 \%$ and $6 \%$ of the total variance respectively (Figure 5). The properties of the multi-decadal components show that they are very stable periodic components because: the two eigenvalues associated with each component are very close to each other in the eigenvalue spectrum, the pairs of eigenvalues associated with each component are well separated from each other, and the two time-EOFs associated with each periodic component are in quadrature.

In order to obtain the corresponding spatial pattern, the correlation maps of the 83 year SSA component (Figure 5(a)) and 67 year SSA component (Figure 5(b)) with annual mean SST (Kaplan et al., 1998) are calculated. Prior to the calculation, a 25 year running mean has been applied to the SST data. Figure 6 displays the maps for the different modes, where a 30 year lag has been introduced in both panels in order to get the same phase as in the EOF analysis (Figure 4). 
(a)

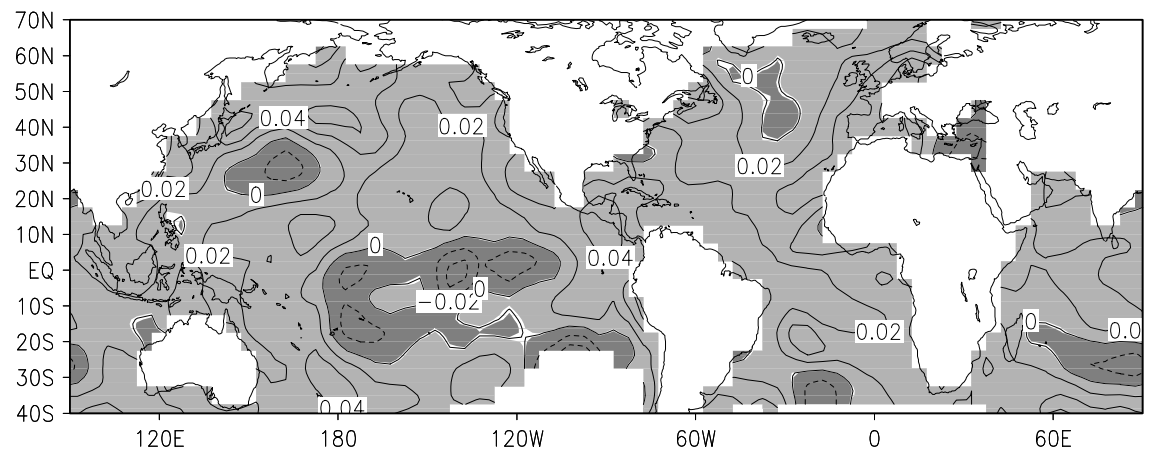

(b)

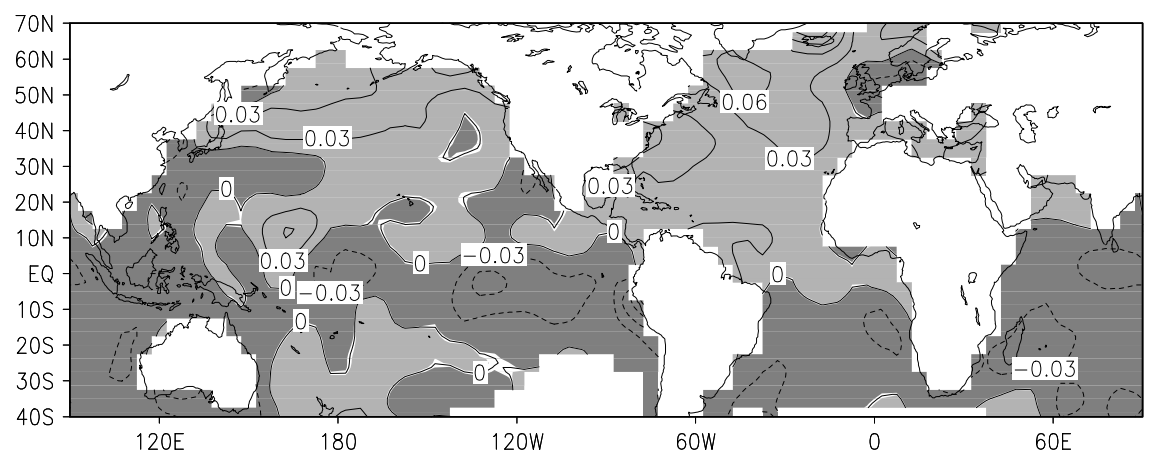

(c)

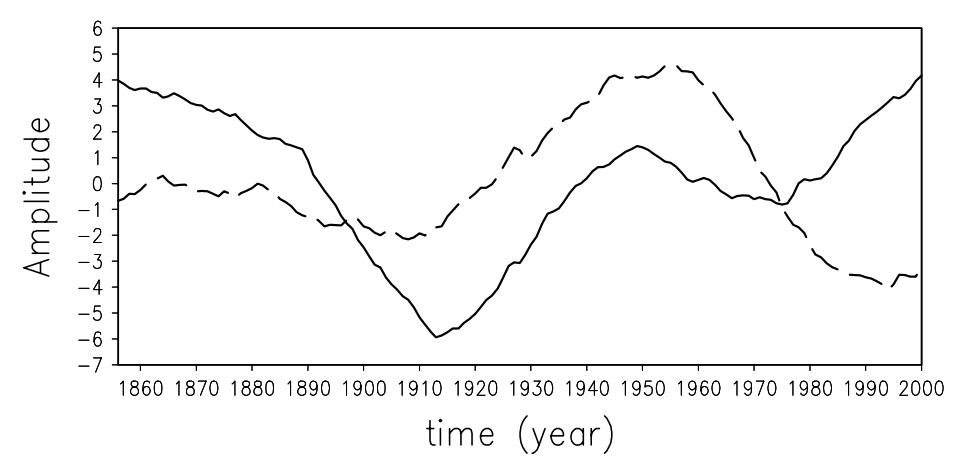

Figure 4. EOF analysis of global annual mean SST provided by Kaplan et al. (1998). Prior to the analysis, the data were detrended and a 25 year running mean has been applied. (a) EOF1 explaining 39\% of the variance. (b) EOF2 explaining 30\% of the variance.

(c) Principal components for EOF1 (solid) and EOF2 (dashed)

\section{DISCUSSION}

\subsection{Temperature signal}

Taking the hemispheric temperature average, one can find a good match between the long-term average surface temperature and the solar cycle; for a review, see Waple (1999). This close correlation could account for the average surface temperature changes in the past, and could partly explain the cold periods around 1700, 1810, 1900, the anomalous warm 1940s and the slight cooling phase between 1950 and 1975 (Jones, 1994). The climate sensitivity is estimated to be a temperature anomaly of $0.2 \mathrm{~K}$ per $0.2 \mathrm{~W} \mathrm{~m}^{-2}$ solar forcing reaching the surface. Therefore, the observed temperature variations are rather high and cannot be explained by a direct radiation effect. Indeed, our analysis suggests that the influence of the solar forcing onto climate is via atmospheric modes of variability. 

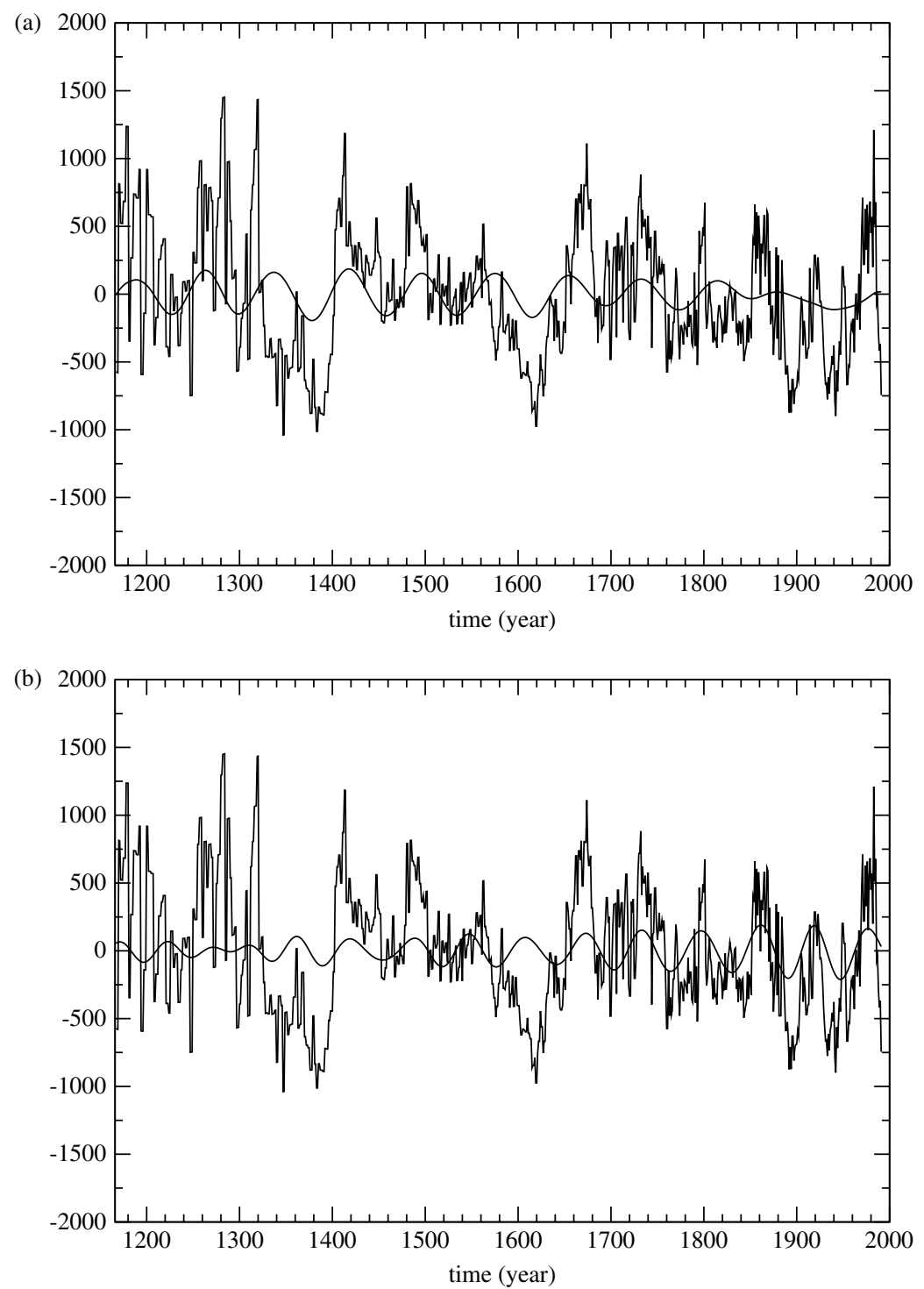

Figure 5. The thin black lines in both panels show the detrended time series of planktonic foraminifera Globigerina bulloides per gram of sediment from Cariaco basin (Black et al., 1999). The thick solid lines are the SSA period components with (a) 83 year period explaining $8 \%$ of the total variance, and (b) 67 year period explaining $6 \%$ of the total variance. They are obtained as the third and fourth components of the SSA analysis respectively

We detect the Schwabe, Hale, and Gleissberg cycles in the solar irradiance forcing. It is found that the patterns of SST associated with these cycles are similar when considering different time scales (Figure 2). For all time scales considered, the SST maps over the Pacific area are consistent with a poleward shift of the subtropical jet and a horizontal expansion, but weakening of the Hadley cell (Figure 2) consistent with modelling studies (Haigh, 1999).

The first EOF for multi-decadal time scales largely resembles the solar fingerprint. The principal component of the first EOF (Figure 4c) suggests that the warming trends since the 1970s and prior to 1940 are in accord with the Gleissberg cycle (Hoyt and Schatten, 1997). The correlation maps suggest that the multi-decadal variability associated with solar irradiance is not confined to the Northern Hemisphere (Figure 2(c)), with modelling studies raising possible links with the tropical Pacific Ocean (Shindell et al., 2001a,b). Even a weak 
(a)

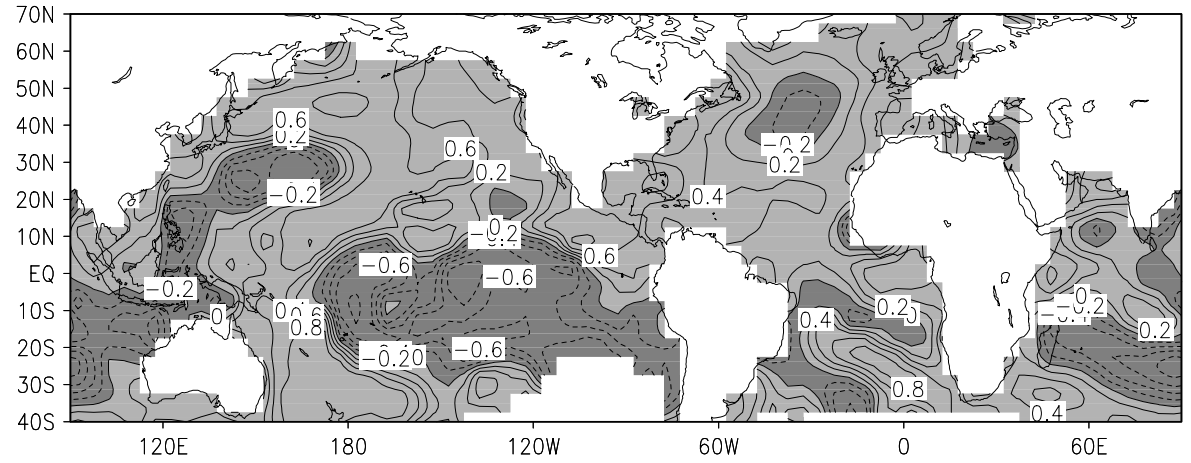

(b)

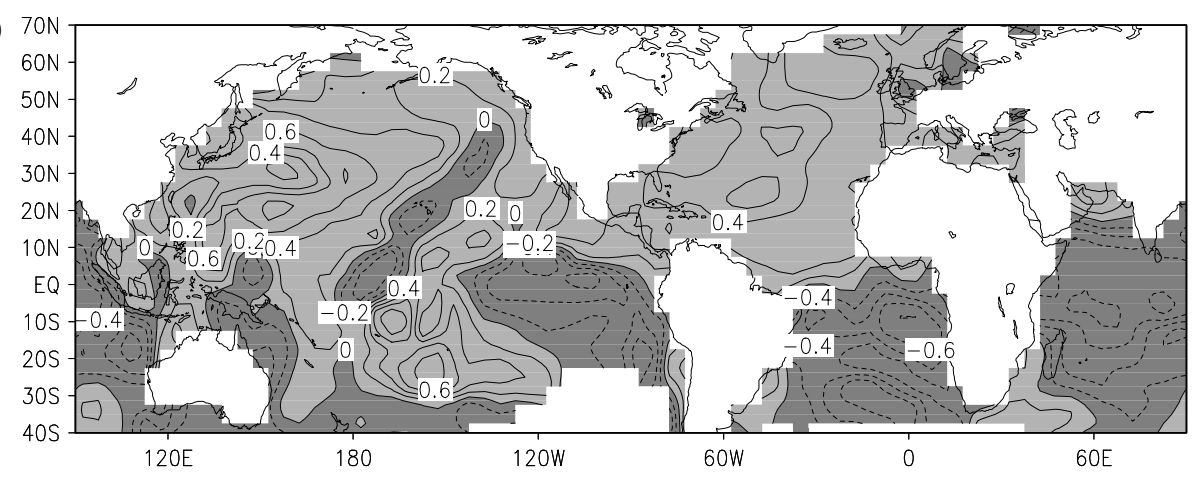

Figure 6. (a) Correlation map of (a) the 83 year and (b) 67 year SSA components (Figure 5) with annual mean SST (Kaplan et al., 1998) covering the period 1856-1997. The SST data are detrended prior to the correlation. For both panels, a 30 year lag has been introduced in order to get the same phase as in Figure 4

increase of SST due to direct solar forcing may enhance convection. Consequently, the Walker circulation is increased and the associated surface westward anomalous wind may be responsible for the negative SST. An increased Walker cell would be consistent with the out-of-phase relation between the Walker and Hadley cells (Wang and Weisberg, 1998).

The second EOF (Figure 4(b)) has a distinct pattern from the solar fingerprint (Figures 2 and 4(b)). This mode is characterized by the interhemispheric seesaw temperature pattern (Crowley, 1992; Stocker, 1998; Lohmann, 2003) associated with the Atlantic thermohaline circulation. The multi-decadal mode is characterized by a monopolar SST pattern in the North Atlantic (Deser and Blackmon, 1993; Delworth and Mann, 2000). In considering the fields of SLP, an anomalous cyclonic circulation was present in the atmosphere during the warm period and an anomalous anticyclonic circulation was present during the cold period. Unlike the dipole pattern seen in the Arctic oscillation signature, the wind anomalies occurred downstream from the SST anomalies. Thus, it appears that the warming is a result of basin-scale forcing independent of the local wind forcing. An additional indication for the Atlantic origin of this mode comes from an EOF analysis for the Atlantic region, where this mode becomes the dominant mode (Dima and Lohmann, 2004b).

A sediment record from the Cariaco basin in the southern Caribbean provides a millennial record of ocean-atmosphere variability in the North Atlantic basin (Black et al., 1999). These records with yearly resolution exhibit strong decadal to centennial climate variability. Distinct modes of documented variability are obtained though our statistical analyses. The patterns have a very similar structure to the maps of solar irradiance and SST (Figures 2(c) and 4(a)) and multi-decadal Atlantic mode (Figure 4(b)). This suggests that a distinction between these two multi-decadal modes of climate variability is possible in the spatial domain (through EOF analysis) and in the temporal domain (through SSA). 


\subsection{SLP signal}

For the decadal time scale, SLP anomalies over large parts of the North Atlantic Ocean are not significantly correlated with solar irradiance (not shown). These results suggest that climate variability on this time scale could be masked by other processes, such as ocean-atmosphere interactions in the North Atlantic realm (Deser and Blackmon, 1993; Dima et al., 2001; Dima and Lohmann, 2004a). The origin of the ocean-atmosphere mode is clearly distinct from the solar mode. However, it appears as the spatial SLP structure related to the North Atlantic oscillation/Arctic oscillation, which is modulated by the solar cycle (Kodera, 2002).

Another explanation for the weak 11 year solar signal is based on the Holton and Tan (1980) mechanisms in modulating the stratospheric circulation and polar vortex due to the quasi-biennial oscillation (Labitzke, 1987; Loon and Labitzke, 1999; Loon and Shea, 2000). One may also note that model simulations show a weak response to the 11 year cycle (e.g. Shindell et al., 2001a). These authors conjecture that the climate system may integrate the solar forcing in such a way that the instantaneous response at 11 years is weaker than the response on multidecadal-to-centennial time scales. In the bi-decadal frequency band, the SLP pattern (Figure 3) shows an annular structure with centres north of the Arctic oscillation mode (Thompson and Wallace, 1998), suggesting a polar vortex mechanism. A dynamical link between solar irradiance and the stratospheric polar vortex has been attributed to an interaction between ultraviolet radiation and ozone in the stratosphere (Balachandran et al., 1999).

\section{CONCLUDING REMARKS}

The radiation variations are detected in many climate records (Hoyt and Schatten, 1993, 1997) with possible large-scale consequences (Stanhill and Cohen, 2001). Statistical analyses of instrumental, historical, and highresolution proxy data have been used to investigate systematically the effects of solar irradiance variations on climate variability modes. Consistent climate variability patterns associated with solar irradiance variations over the last few centuries are examined through statistical (correlation, EOF, and SSA) methods.

SST patterns associated with the Schwabe, Hale, and Gleissberg cycles in the solar irradiance forcing show a characteristic band structure over the Pacific Ocean. This structure is consistent with a poleward shift of the subtropical jet and weakening of the Hadley cell (Haigh, 1999). It is shown that the spatio-temporal patterns associated with the solar irradiance forcing are consistently recorded in sediment records from the Cariaco basin in the southern Caribbean covering the last millennium (Black et al., 1999). We find that the Atlantic multi-decadal mode (Deser and Blackmon, 1993; Delworth and Mann, 2000; Dima and Lohmann, 2004b), characterized by an interhemispheric seesaw pattern, is clearly separated from the solar fingerprint. The distinction of these two multi-decadal modes of climate variability is possible in the spatial domain (through EOF analysis) and in the temporal domain (through SSA).

Our study relies on historical and instrumental data sets, and on measurements of solar irradiance. Therefore, the results depend strongly on data coverage and quality. By using different data set and methods, we try to overcome this difficulty. Differences between the patterns are possibly due to other modes associated with internal climate variability masking the solar fingerprint. For example, the dominant Atlantic mode on decadal time scales is associated with the Atlantic quasi-decadal mode (Deser and Blackmon, 1993; Dima and Lohmann, 2004a) originating from atmosphere-ocean interactions (Dima et al., 2001). The analyses of instrumental, historical, and proxy data suggest a separation between the climate system response to solar forcing and natural climate variability linked to multi-decadal thermohaline circulation variations.

Cubasch et al. (1997) argued that the observed temperature rise over the most recent 30 and 100 years is larger than the trend in the solar forcing simulation for the same period, indicating a strong likelihood that, if the model forcing and response is realistic, other factors have contributed to the observed warming. Since the pattern of the recent observed warming agrees better with the greenhouse warming pattern than with the solar variability response, it is likely that one of these factors is the increase of the atmospheric greenhouse gas concentration. Separating different climate modes (Hasselmann, 1993) is essential for the evaluation and detection of the possible influence of solar irradiance variations on climate (e.g. Hansen and Lacis, 1990; Hegerl et al., 1997). For the examination of the solar-climate link, one needs long-term measurements (e.g. 
Gilgen et al., 1998) and modelling work; this is particularly so for the upper atmosphere, where the solar influence on climate is strongest (e.g. Haigh, 1999; Shindell et al., 2001a,b). A logical next step would be the identification and separation of the spatio-temporal pattern linked to the anthropogenic effect of greenhouse gas concentrations in the atmosphere from internal climate variability and solar forcing, which is important for the interpretation of climate variability for the past, present, and future.

\section{ACKNOWLEDGEMENTS}

Judith Lean, Alex Kaplan, and Phil Jones are thanked for providing their data. We received funding from the German Federal Ministry for Education and Research through the DEKLIM project. The manuscript benefited from the comments of Klaus Grosfeld and two anonymous reviewers.

\section{REFERENCES}

Balachandran NK, Rind D, Lonergan P, Shindell DT. 1999. Effects of solar cycle variability on the lower stratosphere and troposphere. Journal of Geophysical Research 104: $27321-27339$.

Baldwin MP, Dunkerton TJ. 1999. Propagation of the Arctic oscillation from the stratosphere to the troposphere. Journal of Geophysical Research 104: 30 937-30946.

Basnett TA, Parker DE. 1997. Development of the global mean sea level pressure data set GMSLP2. Climatic Research Technical Note No. 79. Hadley Centre, Meteorological Office, Bracknell.

Beer J, Mende W, Stellmacher R. 2000. The role of the sun in climate forcing. Quaternery Science Reviews 19: 403-415.

Black DE, Peterson LC, Overpeck JT, Kaplan A, Evans MN, Kashgarian M. 1999. Eight centuries of North Atlantic ocean-atmosphere variability. Science 286: 1709-1713.

Christiansen B. 2000. A model study of the dynamical connection between the Arctic oscillation and stratospheric vacillations. Journal of Geophysical Research 105: 29461-29474.

Crowley TJ. 1992. North Atlantic deep water cools the Southern Hemisphere. Paleoceanography 7: $489-497$.

Cubasch U, Voss R, Hegerl GC, Waszkewitz J, Crowley TJ. 1997. Simulation of the influence of solar radiation variations on the global climate with an ocean-atmosphere general circulation model. Climate Dynamics 13: 757-767.

Deser C, Blackmon ML. 1993. Surface climate variations over the North Atlantic Ocean during winter: 1900-1989. Journal of Climate 6: $1743-1753$

Delworth TL, Mann ME. 2000. Observed and simulated multidecadal variability in the Northern Hemisphere. Climate Dynamics 16: $661-676$.

Dima M, Lohmann G. 2004a. Fundamental and derived modes of climate variability. Application to biennial and interannual timescale. Tellus Series A: Dynamic Meteorology and Oceanography 56(4): 229-249.

Dima M, Lohmann G. 2004b. Fundamental and derived modes of climate variability. Application to interdecadal variability. Tellus Series A: Dynamic Meteorology and Oceanography submitted for publication.

Dima M, Rimbu N, Stefan S, Dima I. 2001. Quasi-decadal variability in the Atlantic basin involving tropics-midlatitudes and ocean atmosphere interactions. Journal of Climate 14: 823-832.

Gilgen H, Wild M, Ohmura A. 1998. Means and trends of shortwave irradiance at the surface estimated from global energy balance archive data. Journal of Climate 11: 2042-2061.

Grosfeld K, Lohmann G, Rimbu N, Lunkeit F, Fraedrich K. 2004. North Atlantic atmospheric response to multidecadal sea surface temperature variability: observations, models, and proxy data. Journal of Climate submitted for publication.

Haigh JD. 1999. A GCM study of climate change in response to the 11-year solar cycle. Quarterly Journal of the Royal Meteorological Society 125: 871-892.

Hansen JE, Lacis AA. 1990. Sun and dust versus green-house gases: an assessment of their relative roles in global climate change. Nature 346: $713-719$

Hasselmann K. 1993. Optimal fingerprints for the detection of time dependent climate change. Journal of Climate 6: $1957-1971$.

Hegerl GC, Hasselmann KH, Cubasch U, Mitchell JFB, Roeckner E, Voss R, Waszkewitz J. 1997. Multi-fingerprint detection and attribution analysis of greenhouse gas, greenhouse gas-plus-aerosol and solar forced climate change. Climate Dynamics 13: 613-634.

Holton JR, Tan T. 1980. The influence of the quasi-biennial oscillation on the global circulation at 50 mb. Journal of the Atmospheric Sciences 37: 2200-2208.

Hoyt DV, Schatten KH. 1993. A discussion of plausible solar irradiance variations, 1700-1992. Journal of Geophysical Research 98: $18895-18906$.

Hoyt DV, Schatten KH (eds). 1997. The Role of the Sun in Climate Change. Oxford University Press: New York.

Jones PD. 1987. The early twentieth century Arctic high — fact or fiction? Climate Dynamics 1: 63-75.

Jones PD. 1994. Hemispheric surface air temperature variations: a reanalysis and an update to 1993. Journal of Climate 7: $1794-1802$.

Kaplan A, Cane M, Kushnir Y, Clement A, Blumenthal M, Rajagopalan B. 1998. Analyses of global sea surface temperature 1856-1991. Journal of Geophysical Research 103: 18 567-18 589.

Kodera K. 2002. Solar cycle modulation of the North Atlantic oscillation: implication in the spatial structure of the NAO. Geophysical Research Letters 29: 1029-1032.

Labitzke K. 1987. Sunspots, the QBO and stratospheric temperature in the north polar region. Geophysical Research Letters 14: $535-537$.

Lean J, Beer J, Bradley R. 1995. Reconstruction of solar irradiance since 1610: implications for climate change. Geophysical Research Letters 23: 3195-3198. 
Lean J, Rottman GJ, Kyle HL, Woods TN, Hickey JR, Puga LC. 1997. Detection and parameterization of variations in solar mid and near ultraviolet radiation (200 to $400 \mathrm{~nm}$ ). Journal of Geophysical Research 102: 29 939-29956.

Lohmann G. 2003. Atmospheric and oceanic freshwater transport during weak Atlantic overturning circulation. Tellus Series A: Dynamic Meteorology and Oceangraphy 55: 438-449.

Loon H, Labitzke K. 1999. The 10-12 year atmospheric oscillation. Meteorogische Zeitschrift 3: 259-266.

Loon H, Shea DJ. 2000. The global 11-year solar signal in July-August. Geophysical Research Letters 27: $2965-2968$.

Luterbacher J, Xoplaki E, Dietrich D, Rickli R, Jacobeit J, Beck C, Gyalistras D, Schmutz C., Wanner H. 2002. Reconstruction of sea level pressure fields over the eastern North Atlantic and Europe back to 1500. Climate Dynamics 18: 545-561.

Parker DE, Jones PD, Bevan A, Folland CK. 1994. Interdecadal changes of surface temperature since the late 19th century. Journal of Geophysical Research 99: 14373-14399.

Parker DE, Folland CK, Jackson M. 1995. Marine surface temperature: observed variations and data requirements. Climatic Change 31: $559-600$.

Shindell DT, Schmidt GA, Miller RL, Rind D. 2001a. Northern Hemisphere winter climate response to greenhouse gas, ozone, solar, and volcanic forcing. Journal of Geophysical Research 106: 7193-7210.

Shindell DT, Schmidt GA, Mann ME, Rind D, Waple A. 2001b. Solar forcing of regional climate change during the Maunder Minimum. Science 294: 2149-2152.

Stanhill G, Cohen S. 2001. Global dimming: a review of the evidence for a widespread and significant reduction in global radiation with discussion of its probable causes and possible agricultural consequences. Agricultural and Forest Meteorology 107: 255-278.

Stocker TF. 1998. The seesaw effect. Science 282: 61-62.

Thompson DJ. 1982. Spectrum estimation and harmonic analysis. Proceedings of the IEEE 70: 1055-1096.

Thompson DWJ, Wallace JM. 1998. The Arctic oscillation signature in the wintertime geopotential height and temperature fields. Geophysical Research Letters 25: 1297-1300.

Trenberth KE, Paolino Jr DA. 1980. The Northern Hemisphere sea-level pressure data set: trends, errors and discontinuities. Monthly Weather Review 108: 855-872.

Vautard R, Ghil M. 1989. Singular spectrum analysis in nonlinear dynamics with applications to paleoclimatic time series. Physica D 35: $395-424$.

Von Storch H, Zwiers FW. 1999. Statistical Analysis in Climate Research. Cambridge University Press.

Wang C, Weisberg RH. 1998. Climate variability of the coupled tropical-extratropical ocean-atmosphere system. Geophysical Research Letters 25: 3979-3982.

Waple AM. 1999. The sun-climate relationship in recent centuries: a review. Progress Physical Geography 23: 309-328. 